\title{
Micro-lecture Application in College Ideological and Political Theory Teaching
}

\author{
Yongcai Yang \\ Hubei University of Science and Technology, Xianning, Hubei, China \\ 153432804@qq.com
}

Keywords: Ideological and political theory; micro-lecture; college; teaching

\begin{abstract}
Micro-lectures generated by sufficient integration of information technology and education are widely applied in teaching. Application of micro-lectures in college ideological and political theory teaching has conformed to the needs of development of the times, and enhanced college teaching reform. This article introduces micro-lecture meaning and characteristics, analyzes certain deficiencies in college ideological and political theory micro-lecture, and suggests certain countermeasures to optimizing college ideological and political theory micro-lecture, exploring college ideological and political theory relevance and timeliness.
\end{abstract}

\section{Introduction}

College ideological and political theory serves as the basis for college student ideological and political education, focusing on college student socialist core values, morality education and growth. The 21st century is the era of information technology, witnessing integration of information technology and education, and micro-lecture. Implementing micro-lecture as an innovative classroom teaching method in college ideological and political theory is of great significance for its quality.

\section{Micro-lecture meaning and characteristics}

"Micro-lecture" first came from abroad. In a broad sense, "micro-lecture" is also called "micro-lecturing", "micro-teaching" and "micro-course". The earliest development and promotion of "micro-lecture" in China should be originated from Hu Tiesheng, Foshan City, Guangdong Province, pointing out that "micro-lecture is a carrier focusing on micro teaching videos, meticulously designed and developed micro high-quality learning resource based on subject knowledge and skill points (such as knowledge points, skill points and emotional points) or in combination with certain teaching elements and links (such as goals, introductions, activities and evaluations).”

Micro-lecture is characterized by clear goals, highlighting priorities, short and refined texts, and share-ability. Micro-lecture can apply its own characteristics to design teaching contents as theme-based unit scenes, integrating previous single resource categories such as teaching materials, courseware, case and other teaching resources, making teaching contents vivid through micro-videos, highlighting priorities and difficulties, improving teaching quality and student learning efficiency.

\section{Deficiencies in college ideological and political theory micro-lecture}

Compared with traditional teaching, college ideological and political theory micro-lecture witnesses multiple advantages and certain disadvantages such as insufficient practical application and popularity. 


\section{(A) Awareness}

This problem was first manifested in the fact that micro-lecture was not properly valued by college ideological and political teachers. For example, according to the teaching survey reports of Nie Chenxiang and Yang Wei, only 13.15\% of ideological and political teachers not involved in micro-lecture for more than 1 year. Most of them failed to get involved in real micro-lecture. They got familiar with micro-lecture concepts and development only through media or publicity channels. Micro-lecture did not become normal. Furthermore, some teachers only got familiar with micro-lecture micro, short, and small characterizations, failing to really grasp its essence. For example, some "micro-lecture" videos were simply derived from clips of original classroom teaching practices. The content presentation failed to be concise, characterized by obvious jumps and inconsistencies. For example, some teachers began to get involved in micro-lecture, focusing on techniques of micro-lecture manufacture, lacking sufficient attention to micro-lecture content design, leading to its poor quality. In addition, micro-lecture failed to have clear cues for video techniques, lacking obvious introduction of topics or summary of key concepts.

(B) Manufacture

Micro-lecture manufacture techniques were not yet mature. For example, some teachers manufactured videos and audios by themselves, which, due to limitations of techniques, suffered unsightly pictures, improper clips, unclear recorded voices, multiple noises or improper sounds. Some teachers relied on professional editors. But insufficient techniques in video recording, shooting, and editing, and improper technical training limited their authority to participate in editing. Multiple innovative ideas failed to be achieved. Furthermore, micro-lecture timing was not properly mastered, either too long or too short, failing to reflect the micro-lecture "micro, short, and small" characteristics, constantly attract audience, or failing to reflect knowledge integrity and logic. In addition, improper selection of micro-lecture topics, either too large or too simple, made it unsuitable or unnecessary.

(C) Management

Usually, multiple colleges have sound teaching management systems, such as teacher evaluation and assessment systems and educational management systems. However, micro-lecture emerged recently failed to have specific and comprehensive management systems, evaluation systems, systematic planning and top-level designs for its establishment and development, leading to poor coordination and repetition, insufficient specialization and systematic systems and poor quality. Multiple teachers made repeated micro-lecture productions arbitrarily, totally unsystematic. Improper management caused insufficient standards for micro-lecture in class, faultiness in standardization or systematization. Insufficient management systems resulted in insufficient corresponding evaluation systems, and poor command, evaluation, and feedback effects, and poor quality. Therefore, it is necessary for most colleges to establish a scientific and reasonable micro-lecture management system.

\section{Countermeasures to optimize applications of college ideological and political theory micro-lecture}

Against problems in micro-lecture applications, current studies have put forward the following targeted solutions:

(A) Concept improving

1. Recognizing micro-lecture importance is a prerequisite for micro-lecture applications. The 21st century is an era of information technology. Micro-lecture is something new created by the 
combination of development of information technology and era of education reform, meeting people's needs for learning methods and learning resources. Micro-lecture is bound to become normal for information society to cultivate talents. Combination of micro-lecture and college ideological and political theory is a general trend.

2. It is necessary to recognize micro-lecture connotation and essence, and scientifically manufacture and apply it. Micro-lecture supports mixed learning, mobile learning, fragmented learning and multiple novel personalized learning methods and web-based teaching and research methods, focusing on short and elaborate micro-streaming teaching videos, serving as a contextualized, interesting and visualized digital learning resource package carefully designed and developed against certain knowledge or teaching link. In micro-lecture designing, it is necessary to ensure "micro" in both form and content, making students easily learn and master.

3. In micro-lecture designing, it is necessary to take the knowledge point as a unit. In essence, micro-lecture is the micro-video based on knowledge points, quite different from classroom teaching modes based on chapters and sections. Therefore, in micro-lecture designing, it is necessary to handle the relationships between chapters, sections and points. After defining the topics of micro-lecture, it is necessary to split teaching contents into series of knowledge points in a problem-oriented manner, and then making these knowledge points into micro videos. The micro-lecture designing should reflect the principles of 'task-driven, problem-oriented, and feedback-interaction”, creating situations, attracting people, gradually advancing, grading clearly and appropriately summarizing. Only in this way could knowledge points be clearly expressed in a very short period of time.

(B) Techniques optimizing

In the micro-lecture teaching modes, micro-lecture manufacture is crucial, with its techniques determining its quality, which directly influences its effect. It is necessary to gradually improve its manufacture techniques, conducting training and popularity, and centering on specialization. It is proper to upgrade micro-lecture manufacture techniques in the following 3 aspects:

1. Applying techniques to improve micro-lecture quality, improving the quality of screen recording software and mapping software, improving recording with traditional recording methods or shooting and editing with video recording methods, and improving other techniques, making micro-lecture video presentation diversified, editing elaborate and specialized, ensuring screen vividness and richness, achieving synchronization of lectures, blackboard writing and PPT and ensuring sound video results.

2. It is necessary to have micro-lecture manufacture timely, applicable and appropriate. In college ideological and political theory, it is necessary to follow the principles of optimization, appropriately applying micro-lecture and its amount of knowledge and information so as to meet the requirements. Blindly increasing surplus amount of information will make students accept with difficulty, failing to keep up with teaching steps and ensure micro-lecture quality.

3. It is necessary to conduct teacher training. To improve micro-lecture concepts and application skills of its specific tools, it is necessary to conduct corresponding training, such as application of web resources, integration of cases, use skills of micro-lecture tools. Training should be based on practice, making teachers conduct constant practice, evaluation, reflection and promotion.

(C) Management strengthening

To develop college ideological and political theory, it is recommended to establish special management departments, standardizing and systemizing them. The following are some specific suggestions: 
1. It is suggested that college related Party and government administrative departments and ideological and political theory departments (School of Marxism or other responsible departments) should jointly establish the leadership mechanism for ideological and political micro-lecture. College ideological and political theory can not be separated from teachers, and cooperation and support of relevant departments. It is a systematic project, requiring unified leadership and support for fine results. Micro-lecture planning, publicity, and promotion require support and cooperation of the Publicity Department, and its class-hour calculation, assessment method development require support of the Academic Affairs Department, and micro-lecture recording, manufacture of web pages, its platform renewal and maintenance, teacher information technology training require support of the information center, micro-lecture manufacture and competition and other related funds require support of the Financial Department. Only by establishing a joint leadership mechanism could we effectively improve micro-lecture manufacture, mobilize work enthusiasm and play its due role.

2. It is necessary to conduct teamwork in the development of the ideological and political micro-lecture, exerting personal advantages of each teacher. The most important is the ideological and political theory teaching department itself, which should actively organize teachers to carry out micro-lecture design, manufacture, and application, and make teachers get familiar with learning trends and needs, promoting the interaction between teachers and students, promptly updating micro-lecture contents, improving attractiveness and effectiveness, actively coordinating with relevant departments, ensuring smooth development of the ideological and political micro-lecture and achieving expected effectiveness.

3. It is necessary to establish the micro-lecture professional teaching and communication platform, establishing related columns, actively promoting exchanges between teachers, and jointly developing common progress.

\section{Acknowledgments}

This article research was funded by "Party Building and College Student Ideological and Political Research Project Fund" of Hubei University of Science and Technology (Project No.: 2016-17Xdj14)

\section{References}

[1] Zhao Junya, Exploration and Practice of Micro-lecture in College Ideological and Political Theory [J] Journal of Yellow River Conservancy Technical Institute, 2016(1):72-74

[2] Qiu Qiuyun, Exploration of Application of Micro-lecture in College Ideological and Political Theory [J] Journal of Hebei Radio \& TV University, 2017, 22(2):78-81

[3] Wang Yanhua, Exploration of Micro-lecture Application in College Ideological and Political Theory [J] Educational Modernization, 2016(34)

[4] Zhang Miao, Analysis of Micro-lecture Application Design in College Ideological and Political Theory--Taking Ideological and Moral Cultivation and Legal Basis as Example [J] Journal of Yangtze Normal University, 2015, 31 (4) ): 126-130

[5] Sun Zhongliang, Wang Feixia, Research and Application of College Ideological and Political Theory "Micro-lecture" Teaching Model [J] Study of Ideological and Political Course, 2014(6):31-34 
[6] Chen Hua, Development and Application of Micro-lecture in College Ideological and Political Theory [J] Heihe Journal, 2015(9):110-111

[7] Zheng Guoyu, Li Liang, Some Problems and Their Thinking in the Design of College Ideological and Political Theory--Taking Entries in National College Micro-lecture Competition as Example[J] Journal of Ideological \& Theoretical Education, 2016(6): 66-69 